\title{
Teaching Dyslexics Students with the Targeted, Individual, Structured, Integrated Program in the Lesson of History
}

\author{
Maria Drossinou Korea ${ }^{1,2}$, Helen Mintza ${ }^{3, *}$, Ioannis Stavrou $^{3}$ \\ ${ }^{1}$ Special Education and Training, Faculty of Humanities and Cultural Studies, University of the Peloponnese, Greece \\ ${ }^{2}$ Faculty of Philology, East Center-Old Camp, Kalamata, Greece \\ ${ }^{3}$ University of Peloponnese, Kalamata, Greece
}

Received November 26, 2019; Revised March 30, 2020; Accepted May 13, 2020

\section{Cite This Paper in the following Citation Styles}

(a): [1] Maria Drossinou Korea, Helen Mintza, Ioannis Stavrou, "Teaching Dyslexics Students with the Targeted, Individual, Structured, Integrated Program in the Lesson of History," Linguistics and Literature Studies, Vol. 8, No. 6, pp. 277 - 284, 2020. DOI: 10.13189/lls.2020.080601.

(b): Maria Drossinou Korea, Helen Mintza, Ioannis Stavrou (2020). Teaching Dyslexics Students with the Targeted, Individual, Structured, Integrated Program in the Lesson of History. Linguistics and Literature Studies, 8(6), 277 - 284. DOI: $10.13189 / 1$ s.2020.080601.

Copyright $\odot 2020$ by authors, all rights reserved. Authors agree that this article remains permanently open access under the terms of the Creative Commons Attribution License 4.0 International License

\begin{abstract}
Specific learning difficulties (dyslexia) are examined as a neurodevelopmental disorder according to the educational and teaching dimensions resulting from the effective or the ineffective coping with the difficulties of the school. In this editorial we will describe and analyze some recent findings in this field, also deriving from the change of diagnostic criteria proposed in 2013 by the American Psychiatric Association in DSM-5 that has led to an increase in the number of students that meet diagnostic criteria and that has led to an increase of the level of the heterogeneity of their functional profiles. Especially in secondary education the subject has implications for the future career of the pupils. The philologist who has expertise in the special educational needs by educational Greek law support the difficulties of his pupils. So, he should know the appropriate pedagogical tools to understand and support them. The aim of the research is to study the teaching intervention dyslexic pupils with emphasis on the memory difficulties in the course of the history. The pedagogical tool as the Targeted, Individual, Structured, Integrated Program for Special Educational Needs (TISIPfSEN) used in the primary and secondary teaching programs in the inclusion school systems. The pedagogical experiment of the special teaching methodology of TISIPfSEN was implemented in a certain case of a 3rd grade of Gymnasium student who intervened
\end{abstract}

in the history lessons. The research issue was demonstrated in part because it requires the philologist to have been trained in the provision of the TISIPfSEN training tool in the difficulties of language, which is not always the case in undergraduate or postgraduate studies. In the case where the philologist himself has been trained in the TISIPfSEN methodology, he has emerged that he can design and implement the suitably adapted and differentiated intervention program with an emphasis on text comprehension. In the conclusions, we underlined that through the implementation of TISIPfSEN, the student succeeded in achieving the educational target we set by presenting an improvement in reading and understanding texts.

Keywords Dyslexia, TISIPfSEN, Dyslexia, Mnemonic Skills

\section{Introduction}

\subsection{Clarifying the Term Learning Difficulties}

Specific Learning Difficulties (Dyslexia) are lexicographed in Greek language as the failure to learn and 
understand what you are reading. However, there is a clear lack of consensus among teachers, psychologists [1] and doctors on exactly how they describe reading difficulties, especially on the causal performance of the situation [2]. Dyslexia is the most studied and the most known learning disorder in the world but there is only a relative agreement on the definition and on the diagnostic criteria used in clinical and research fields. Dyslexia refers mainly to the difficulties in learning to read and, even if it is generally diagnosed in the first years of schooling, it can have different clinical manifestations in different phases of life and it can also influence different dominions of life. Then, we will discuss some issues for future researches mainly in the field of specific interventions in general secondary schools. Thus, the cognitive elements of perception, memory function, graphomotor space, reading, arithmetic, and behavior that they have to support determine exactly how poor a reading ability is so to be diagnosed with dyslexia. Typically, this is considered a specific learning difficulty (dyslexia) and the term is used to be excluded for students with significant deviations from the baseline reading level that is credited to a certain semester of formal and compulsory schooling. It is underlined that in dyslexia excludes a number of indications such as general debilitating disorder, mental retardation, major brain injury, or other serious emotional problems or aggravating cultural factors such as the student coming from a house that the spoken language is different from that which is used by the local community and the wider the official state. Synonymous terms are developmental reading disorder and developmental dyslexia [3].

In bibliographic references [4] the terms such as acquired dyslexia are met to identify the specific learning difficulties (SLDs) in a person who previously read and understood text [5], direct dyslexia as a form of acquired dyslexia in which the student can read loud words but can not understand them. So, dyslexia refers mainly to the difficulties in learning to read and, even if it is generally diagnosed in the first years of schooling at the end of the second year of the primary school. So, it can have different clinical manifestations in intelligence, different phases of life and it can also influence different dominions of life [1]. It is estimated that about $5 \%-15 \%$ of students are likely to have a reading disorders, with different estimations according to the specific diagnostic criteria used [2], [3]. Still, the term phonological dyslexia is seen as a form of acquired dyslexia, characterized by difficulties in learning to hear the words loud. Phonological dyslexic students can read using the full word method but have difficulties in new words or names they have not met before [6]. In 1963 Kirk defined dyslexia as a kind of learning disability and defined learning disabilities as "an unexpected difficulty in learning one or more of one instrumental school abilities" [4]. Since this seminal work of Kirk [5], the idea of "an unexpected difficulty" has influenced research and clinical field, with a double interpretation of the idea of "unexpected difficulty", both interpretations are related to the "principle of discrepancy". Also, according the neuropsychology the surface dyslexia is referred to as a form of acquired dyslexia characterized by difficulties in recognizing and obtaining the meaning of a word. The student with Surface dyslexia read out loud and careful words to understand them. Hence they have difficulties with the spelling of difficult words such as the tilting of irregular verbs [7]. Finally, teaching Intervention in linguistic is aimed to facing in the secondary education with dyslexia in continuing the teaching in the primary. Well, as we know the comprehensive cognitive assessments are not necessary for the identification and treatment of learning disabilities [6].

\subsection{Memory Development Theories}

Memory works through three basic processes: encoding, storage and retrieval information [8]. Initially, we have the encoding of the information in two types, the verbatim encoding, memorizing words and phrases, or the gist encoding, memorizing the meaning of the events [9]. Then the information is stored in the memory for future use and finally when it is necessary to remember the information, we have the recovery it from the memory. Good memory function means good operation and coordination of all these three parts. An application in the Memory Development Theories be focused in the Number of Serial Phonological units, in the Spelling of word as the "HISTORY" and the Memory of Serial phonological sounds is In essence, the person has learning to decode what he reads at the level of the phonological unit of consonant (C) and vowel (V) and to encode it quantitatively as in the example with the phonological decoding of the word "history" consisting of seven phonological units which have been set up with a serial and certain number of consonants (C) and vowels (V)

\begin{tabular}{|l|l|l|}
\hline $\begin{array}{l}\text { Number: Serial } \\
\text { Phonological units }\end{array}$ & $\begin{array}{l}\text { Spelling of } \\
\text { word }\end{array}$ & $\begin{array}{l}\text { Memory: Serial } \\
\text { phonological sounds }\end{array}$ \\
\hline 1 & H & consonant (C) \\
\hline 2 & I & vowels (V). \\
\hline 3 & S & consonant (C) \\
\hline 4 & T & consonant (C) \\
\hline 5 & O & vowels (V). \\
\hline 6 & R & consonant (C) \\
\hline 7 & Y & vowels (V). \\
\hline
\end{tabular}

In childhood and adolescence, we do not have full development of mnemonic skills but gradual. This is because memory evolves into four areas in terms of changes in basic processes and capacities, in strategies, in metacognition, and in content knowledge. The basic processes and capacities are already evident from infants who remember, recognize things and situations, recover information from memory [10]. Until the age of 3 months, 
they have learned to remember event lists (sleeping and food routines), to make associations and generalize, even having some insight when they are looking for and seeking to find a game. Nevertheless, processing capacity and speed are evolving and improving throughout the child's development. The cognitive amount of information a child can process and the time it takes to recall the information is continually improving without, however, knowing clearly whether this is due to neurodevelopmental changes and their relationship to memory capacity or other improvements. The impact of motivation to read on reading gains for struggling readers with and without learning disabilities examine the raising the reading skills of secondary-age students with severe and persistent reading difficulties. So, the evaluation of the efficacy and implementation of a phonics-based intervention programmer and the effects of classroom practices on reading comprehension, engagement, and memory motivations for adolescents [7].

The use of memory strategies is widened between the age of five and adolescence [8]. As a strategy, we define cognitive activities that occur voluntarily and enhance memory performance [11]. These are various kinds of strategies such as rehearsal, organization of thought and selective attention. Students who have learned and use such strategies usually remember more than those who do not use them. However, changes in the quality of the strategies and the range of situations that they used are far beyond those ages. Overall, learning these strategies seems to represent an important part of the development of memory, especially in the middle childhood and beyond.

The term metacognition refers to the later knowledge of the students about memory [8]. The development of metacognitive knowledge is evident especially between the ages of 5-10 years. However, from the infancy to the end of elementary education, that is the last grade of elementary school, the fourteenth (14th) semester of formal and compulsory education from the kindergarten, there is also an obscure metacognitive knowledge [8]. Metacognition includes two separate types of knowledge: explicit and implicit. Explicit knowledge of memory is conscious and comprehensible and includes real knowledge of strategies, tasks and abilities. Implicit knowledge, on the contrary, is not conscious or comprehensible, and includes procedures such as monitoring one's comprehension and the feelings of knowing [9].

Knowledge of related content greatly affects the memory of pupils at all ages [8]. By content knowledge we refer to all the knowledge we acquire about the material we store in memory. This knowledge influences to remember more, to executing the basic processes of memory, to learning of new memory strategies and metacognitive knowledge. By the term content knowledge, we do not refer to information and information material [12] but to all the knowledge we gain about the process of memorizing and understanding the parts from which the contents of the text we have read are comprehended.

\subsection{Clarifying the Term of the Targeted, Individual, Structured, Integrated Program for Students with Special Educational Needs (TISIPfSEN)}

Research suggests that reading engagement and motivation are strong predictors of reading performance [10]. The reading motivation may decline as students' adolescence, with dyslexia resulting in less time spent with text as the history. The pedagogical tool of the Targeted, Individual, Structured, Integrated Program for Students with Special Educational Needs (TISIPfSEN) [13] is applied the observing methodology, intervention methodology of pupils with special educational needs and the methodology of special teaching. The TISIPfSEN is evolving and being implemented in five distinct phases.

The methodology of observation [14] of the specific learning difficulties (SLDs) is applied in the first and the second phase. So, in the first phase, the systematic empirical participatory observation takes into account the individual, family and school history of the student as well as the data recorded in the report of the Diagnostic Center for Differentiating and Support of Learning Difficulties [15]. In the second phase, the Informal Pedagogical Assessment is implemented through the methodology of observations for the special educational needs with emphasis the student with dyslexia. The pupil's abilities and spelling difficulties are recorded with checklists of reading and meaning control skills in the text from the history lesson. It is happened because the philologist has the responsibility of teaching the courses from history book and he must clarify the teaching priorities according the second phase of the pedagogical tool 's TISIPfSEN specific learning interventions.

The third phase of TISIPfSEN refers to the formulation of the teaching goal and the design of the curriculum. In this the philologist according, the observations put the learning priorities for the lesson of history. So, he describes the pedagogical differentiations to the teaching task, the teaching goal, the time of teaching intervention, the task analysis of goal, the adapted materials, the criteria of teaching success. The methodology of intervention of the specific learning difficulties (SLDs) is applied in the third and the fourth phase. Especially in the fourth phase, the philologist applies with the same concept of intervention methodology, also the methodology of special teaching for the management the inclusion of the special educational needs. In these phases the teaching intervention methodology is implemented with the adapted differentiations as the text memory techniques by using the "shoe-boxes" which modifying as pedagogical cognitive machine.

Finally, in the fifth and last phase the evaluation of the student's progress and self-evaluation of the teacher through self-observation and pedagogical reflection is 
made. In this the philologist applies with the same concept of observation methodology, the intervention methodology, also the methodology of special teaching to estimate the teaching results for the SLDs.

\section{Materials and Methods}

\subsection{The Aim of the Research}

The aim of our research is to study the diversified teaching intervention of pupils with Specific Learning Difficulties as known as dyslexia through a Targeted Individual Teaching Structured, Inclusive, Intervention Program for Special Education Needs (TISIPfSENs) in the understanding of texts [16] in the history lesson at the third grade of Gymnasium. The problem was based on the initial observations of the philologists and was recorded according to the methodology of special pedagogical strategies on teaching of pupils with special educational needs [17]. The challenge for this study was focused on the philologist's philosophy and capabilities, to be able to practice, to understand the pupils' characteristics with as dyslexia and to support them with the teaching of language courses. Given that the SLDs as dyslexia are investigated as a neurological and neurodevelopmental problem that school required to cope with according to the educational model of special education. That is why in our expediency, we thought that secondary school teachers [18] should know the appropriate pedagogical tools so that they can understand and support the difficulties of their pupils.

\subsection{Research Hypothesis}

The philologist can understand the pedagogical tool of the Targeted Individual Teaching Structured, Inclusive Intervention Program for the pupils with Special education needs (TISIPfSENs) when knows the appropriate pedagogical theories that govern it, the nature and the difficulties of children with Specific Learning Difficulties (SLDs) as well as the operation and development of memory. To understand the structure of the tool, the actions it must take and the purpose of each phase. But also be properly informed about the characteristics of children with dyslexia and how memory works. He will then be able to design and implement his own teaching intervention and help students with dyslexia and memory problems in the lesson of history, leading them to learn historical events, understand different aspects of a historical event, and finally can participate in the teaching process in the classroom.

So the question that we have worked on is whether the philologist can intervene with the Targeted Individual Teaching Structured, Inclusive Intervention Program for the pupils with Special education needs (TISIPfSENs) in the lesson of history, to a student with Specific Learning
Difficulties (SLDs) (dyslexia) with emphasis on the mnemonic skills?

\subsection{Methodological Research}

Our research is bibliographical [14] and empirical with the pedagogical action-research as it consists of both bibliographic data and data we received using the observation methodology and special teachings, according to the pedagogical principles governing special education and training.

The observation methodology followed was based on a case study of a particular student with dyslexia and memory difficulties [14]. With this selection of research strategy, we have the ability to focus on a case study by examining an individual case of a pupil with a particular learning disability and to approach the understanding of its characteristics through its complex context, within the school community and the general class attended by a philologist in pedagogical and teaching action. The importance of strategy it is not only in the solution of practical problems, [17] but in providing alternative ways of identifying and investigating the research problem.

\subsubsection{Teaching Design According to the Third Phase of TISIPfSENs}

The basic research tools of methodology came from the Targeted Individual Teaching Structured, Inclusive Intervention Program for the pupils with Special education needs (TISIPfSENs) and each of them has its own goal. The first tool according to the TISIPfSENs using the systematic empirical observation, with it we have recorded the individual, school, academic, family, social and diagnostic level of the child. This is a case study we based on for our research, Natalia, a girl 15 -year-old who is in the third grade of the Gymnasium with intense monumental difficulties. The student is also diagnosed by the Center for Diagnosis and Support for Differentiating Diagnosis and Support (CfDSDDS) [15]. The observation methodology tools of TISIPfSENs aims to collect information mainly through the senses and experiences. Thus, with the second tool according the TISIPfSENs, using the Informal Pedagogical Assessment (IPA) of information, we were collected data which that helped the philologist to set the teaching priorities in order to design and implement the appropriate intervention program to help our student understand the texts in the history lessons.

The third tool according the TISIPfSENs includes the design of the differentiated teaching program based on the objectives set by the philologist in the role of special teacher in the history lesson. So, in the fourth tool according the TISIPfSENs implements a series of text differentiations. They are focused in the particularly text from the book of "The new Hellenic History" which it is refer in the Greek revolution 1821 and based on teaching 
design. Finally, in the fifth tool according the TISIPfSENs evaluates the reading skills of students and also, the effectiveness of teaching intervention in the understanding and in the correct spelling and copy writing.

The timetable for our teaching intervention for this text are recorded the dates, the start - up time, the duration of the intervention, the frequency and the space that will take place. Specifically, our teaching interventions started on $7 / 5 / 2018$ and ended on 21/5/2018 (a total of 15 days with 45 minutes each time). They took place in the classroom teaching and continuing as individual lesson at home every Monday and Thursday of one hour with the application of our teaching goal 15 minutes each time.

The teaching goal we set was our student to read and restore in memory 25 textbooks lines, about 200 words like the word "Army" type of VCCV (where V is for Vowel and $\mathrm{C}$ is for Consonant), in the history lesson, with about 8 to 10 optical facilitators. But in order to help our student, we "divided the target" into 5 steps [17] [19]:

First Step: Read and restore in memory of the 10 words of the phonological type of VCCVC "Elder" with five phonological units.

Second step: To read and restore in memory 10 words of the phonological type CVCCVC "forces" with six phonological units.

Sixth step: Read and restore in memory of the 15 words of the phonological type "CVCVCCVCCVC" "Papaflessas" with eleven phonological units.

Finally, the diversified pedagogical materials and tools we used over the school book of History of the 3rd High School were the specially designed folder -with rubber and the shoe-cube-three-dimensional cognitive machine supporting memory functions as well as mobile cards with some photos from the book and differentiated texts and words on the particular chapter of the school lesson.

\subsubsection{Implementation of a Diversified Curriculum According to the Fourth Phase of the TISIPfSENs}

The lesson in which the intervention takes place is Section 8, which refers to "The Evolution of the Greek Revolution 1821-1827" in the book of History of the 3rd Gymnasium. The unity in which we drew up our intervention on the Revolution of 1821 has been "devided" into three parts.

We prepared for Natalia a shoe-box for the 3rd Grade History lesson in the second part of Unit 8 "The Evolution of the Greek Revolution 1821-1827" (The Phase of Hits 1821-1824). In order to attract the student's attention to the lesson of history, we dressed in collage the shoe-box, with her favorite objects (wolves, anime series). In this way, the schoolgirl seemed to be interested in the lesson of history even a little - and as we have said and recorded in our intercessions, the lesson of history seemed "less boring" to her.

On the outer top (1) on the shoe cover are the student's details as well as a photograph of the cover of the history book. On one of the four outer sides of the box we created a space for the calendar cards (2) where the student was looking for the appropriate movable card and placing it in a certain position. This was a precondition for exercise in memory skills, since it would recall the positions of the day, the date of the month, and the year that the student placed correctly in each teaching intervention. On another outboard side of the shoe, the student came to mark the start time of the intervention by marking the start time with a marker on a round clock at the end time on another watch next to the line, of interfering with a third clock creating the piece of pizza of the time "(3). Below, the student also placed the clocks for working time calculation in the correct order as a metacognition exercise. Also, on another external side of the shoe, the student notes her feelings (4) she recognizes from some cards, appreciating if she likes what she is studying. In addition to another external side of the shoe, the student is practiced in the neurodevelopmental areas of learning readiness (5) with some cards such as the mouth and ear for the oral speech, the hand for psychomotor, the lamp for mental capacities and the heartbeat for emotional organization. At the bottom of the shoe on the lower outside there is the weekly timetable (6) of the pupil and the time of intervention in the lesson of history. The card that represents the pupil's spatial position is placed in the class and declares its integration into the differentiated lesson of history.

Inside the upper part of the box is placed the teaching task which, in the case of Natalia, was "to read and restore in her memory a text of about 25 rows and 200 words of the phonological type of the word " Army" VCCV in the History lesson with the help of 8 of the visual conceptual facilitators. "And, just below, the educational steps of the differentiated program of special education and training are gradually being put in. So in the 6th step of the intervention, Natalia learns to "read and restore in her memory words like "CVCVCCVCCVC" "Papaflessas". Finally, the inside of the shoebox, which is divided into three parts, is placed in the first (1) the specific differentiated text of our intervention divided into autonomous pieces of meaning. In the second part (2) the movable cards are placed with the visual facilitators that depict exact photographs of the lesson and mobilize the pupil's memorable skills having the role of cognitive ramp. In the third part (3), mobile cards are placed with words and key phrases that help the student to understand the text.

\subsubsection{Assessment of the Targeted Individual Teaching Structured, Inclusive Intervention Program for the Pupils with Special Education Needs (TISIPfSENs)}

After the end of the implementation of the differentiated intervention program in history and based on our heterogeneity from an initial evaluation of the student's needs, the co-shaping of the goals, we proceed to self-evaluation with some self-observation. These refer to records of what the subject, says, makes, thinks and feels in 
front of the student's special learning difficulties, the philologist and is a prerequisite for the evaluation of the progress of the student with the specific teaching objective in the intervention of history.

In the fifth phase of the TISIPfSENs, the progress of Natalia, a high school student, was evaluated, and if she learned to understand a text of about 25 lines, about 200 words, she reads and recalls the words like the word "army" in history lesson, with about 8 to 10 optical facilitators. In the past, we noted that Natalia sometimes did not manage to complete the exercises given within the one-fourth time limit, but at first she seemed stressed. However, Natalia seemed to show significant progress over time and made a major effort to improve continuously. Here, in our self-observation, we also noted our own uncertainty and feelings about a possible failure in the pedagogical experiment we performed with innovative and unprecedented variations in the subject's history lesson for the student.

In one of the steps, we note in the intersections that Natalia was asked to read a section of unit 8 "The Evolution of the Revolution of 1821" in History of the 3d Gymnasium. The student presented pauses while reading, stopped reading in the very big words and spelled it within to read and change the letters of the text as the word "Vrace" instead of the word "Thrace". We split the text into 3 pieces and put the pieces of text alternately into the shoe, we asked Natalia to match the cards that represent events or faces of the text with the corresponding text and the corresponding words and phrases that we have created as cards [20].

She was also given the same text with some blanks and words that the student had to place the mobile cards after reading the words and remembering the position without having the text in front of her, something she did with success. We also asked Natalia this time to fill in the blanks by writing the words this time, also without looking at the original text while. Here, according to our translations, Natalia wrote the words in the given position but did not avoid spelling mistakes. We also prepared a booklet with all the letters of the alphabet and with mobile cards that depicted in alphabetical order, key words in the text, cards with certain visual conceptual facilitators from the text and with the help of the letters "we played" with Natalia the game of the hang glider. We gave Natalia certain letters of the text and we asked her to put the missing letters in order to create the word correctly, something she did but with some misspellings. We also asked her to match the words that were created with the corresponding photos and words and phrases in the text.

\section{Conclusions}

Concluding, our issue about the Teaching Dyslexics Students with the Targeted, Individual, Structured,
Integrated Program in the Lesson of History we have study that Dyslexia is the most known as specific learning disorder in the world [11]. But after more than 120 years from it first description by Pringle Morgan [12] there is only a relative agreement on the definition and on the diagnostic criteria used in literacy difficulties occur for a range of reasons including special educational needs, disaffection and low aspirations fields. After a thorough study, we have come to the conclusion that our research question, which has been a matter of concern to us, is proving to be a condition. Particularly:

If the philologist knows from his undergraduate lessons basic pedagogical principles according to observation and intervention methodology for pupils with dyslexia, he / she can understand memory problems in the causal basis of neurological and neurodevelopmental disorders and textual difficulties resulting from them, highlighting the pupil's abilities. Even the philologist can develop appropriately tailored pedagogical practices in the school, academic community, and family, and manage their difficulties in memory by promoting school integration. Moreover, as a prerequisite, the philologist has been trained in the provision of the TISIPfSENs training tool in texts such as those in the history lesson [13]. In this way, it will be able to implement the theories of memory [8] development and functioning in the pupil with dyslexia [4] and scientifically documented to design an appropriately adapted and differentiated intervention program with an emphasis on text comprehension. The philosopher with the pedagogical tool TISIPfSENs has been able to intervene effectively in the history lesson, to a student with memory problems by implementing the fourth phase of TISIPfSENs, fragmenting the development of the Greek Revolution 1821-1827 into five differentiated teaching steps. At the end of the implementation of the differentiated program of intervention, Natalia learned to understand text of up to 200 words, read and recall correctly the words of a certain phonological type and place it in a certain order within the text. Moreover, the problem of the correct writing of the words according to our hetero-observations has not been dealt with, and for this reason in our self-observation we felt that we need to limit the phonological extent of the words we used. Thus, in the case of the word " "CVCVCCVCCVC" "Papaflessas" of 11 phonological units, we were led into a 10 " revolution ", in order to further strengthen Natalia's positive self-esteem and to further confirm its progress.

However, we must also note the difficulties faced by a philologist in his intervention with TISIPfSENs. With the law on the compulsory education of pupils with a Specific Learning Difficulties [15], the philologist more than any other is obliged to help students with Dyslexia. The teaching interventions of people with special educational needs is properly conducted in the general class and addressed to all pupils. It is noted, therefore, that in the classroom the philologist has to deal with a number of 
negative factors regarding to the large number of children in the classroom, the stressed curriculum for the course curriculum and the limited teaching time. For these reasons, she is invited to organize targeted and systematic teaching of language courses. In conclusion, we consider that it is necessary to extend the research study on memory skills and their assessment because they affect performance in language courses for all pupils with Dyslexia in secondary education.

\section{REFERENCES}

[1] Giofrè D, Toffalini E, Altoè G, Cornoldi C, "Intelligence measures as diagnostic tools for children with specific learning disabilities," Intelligence, no. 61, pp. 140-145, 2017.

[2] Cavendish W, "Identification of Learning disabilities: implications of Proposed DSM-5 criteria for school-based assessment," Journal of Learning Disabilities, no. 46, pp. 52-57, 2013.

[3] American Psychiatric Association, Diagnostic and Statistical manual of mental disorders., Washington DC: APA., 2013.

[4] Kirk SA, Elkins J, "Characteristics of children enrolled in the child service demonstration centers.," Journal of Learning Disabilities, no. 8, pp. 630-637, 1975.

[5] Kirk SA, Educating exceptional children, Boston: Houghton Mifflin, 1962.

[6] Fletcher JM, Miciak J, "Comprehensive Cognitive Assessments are not necessary for the identification and treatment of learning disabilities.," Archives of Clinical Neuropsychology, no. 32, pp. 2-7, 2017.

[7] Melekoglu, M., "Impact of motivation to read on reading gains for struggling readers with and without learning disabilities," Learning Disabilty Quarterly, vol. 34, no. 4, p. 248-261, 2011.

[8] Jeffes, B, "Raising the reading skills of secondary - age students with severe and persistant reading difficulties: evaluation of the efficacy and implementation of a phonics - based intervention programme," Educational Psychology in Practice, vol. 32, no. 1, p. 73-84, 2016.

[9] Guthrie, J. T., \& Klauda, S. L, "Effects of classroom practices on reading comprehension, engagement, and motivations for adolescents," Reading Research Quarterly, vol. 49, no. 4, p. 387-416, 2014.

[10] Cockroft, C. and Atkinson, C., "'I just find it boring': Findings from an affective adolescent reading intervention," Support for Learning, no. 32, pp. 41-59, 2017.

[11] Scanlon, D, "Specific learning disability and its newest definition: which is comprehensive? And which is insufficient?," Journal of Learning Disabilities, no. 46, pp. 26-33, 2013.

[12] Frith, U, "Autism and Dyslexia: a glance over 25 years of research," Perspectives Psychological Science, vol. 8, no. 6, pp. 670-672, 2013.
[13] Courtenay Frazier Norbury, Bruce Tomblin, J., \& Bishop, D., Understanding Developmental Language Disorders: From Theory to Practice, A. Ralli, Ed., Athens: Gutenberg, in greek, 2013.

[14] Conti-Ramsden, G, "Heterogeneity of Specific Language Disorder in Adolescence," in Understanding Developmental Language Disorders, R. Ass, Ed., Athens, Gutenberg, in greek, 2013, pp. 275-301.

[15] Porpodas, K, "Literacy Acquisition In Greek: Research Review of the role of Phonolgical and Cognitive Factors," in Handbook of Orthography and Literacy, New York, Roudledge, 2016, pp. 189-200.

[16] Stasinos, D, "Dyslexia: (Causal) Pathogenesis and Interpretation Models," in Speech and Language Psychology: Development and Pathology. Dyslexia and Speech Therapy, Athens, Gutenberg, in greek, 2015, pp. 293-335.

[17] Nunes, T., Aidinis, Ath., \& Bryant, P, "The Acquisition of Written Morphology in Greek," in Handbook of Orthography and Literacy, New York, Roudledge, 2016, pp. 201-218.

[18] Markakis, E.; Drossinou, M., "Experimental Curriculum for Special Learning Difficulties (Dyslexia)," in Children with Special Needs in Primary School: Theoretical and practical approach, Athens, Diadrasi, in greek, 2011, pp. 321-350.

[19] Porpodas, K, "Reading and Understanding Texts," in Reading. Cognitive Analysis, Psychological Factors, Language Impact, Learning and Teaching, Educational Extensions and Applications, Patras, Self-Edition, in greek, 2002, pp. 403-440.

[20] Siegler, R, "Memory Development," in Children's Thinking, New Jersey, Pentice Hall, 1998, pp. 173-211.

[21] Koliadis, Em, "The long-term memory," in Cognitive Psychology Cognitive Neuroscience: The Information Processing Model, Athens, Gregory, in greek, 2018, pp. $310-418$

[22] Porpodas, K. D., "Memory," in Reading. Cognitive Analysis, Psychological Factors, Language Impact, Learning and Teaching, Educational Extensions and Applications, Patras, Auro-edition, in greek, 2002, pp. 111- 123.

[23] Snowling, M. J. \& Hulme, C, "Intervention Program for Improving Reading Skills in Children with Language-Learning Disabilities," in Understanding Developmental Language Disorders, R. Ass, Ed., Athens, Gutenberg, in greek, 2013, pp. 393-419.

[24] Koliadis, Em, "Theoretical Models of Memory,," in Cognitive Psychology Cognitive Neuroscience: The Information Processing Model,, Athens, Gregory, in greek, 2018, pp. 17 - 93.

[25] Drossinou Korea, M, "The Targeted Individual Teaching Structured, Inclusive Intervention Program for the pupils with Special education needs (TISIPfSENs)," in Special Education and Training. The special education proposal for children and young people with special needs, Patras, Oporttuna, in greek, 2017, pp. 305-377.

[26] Avramidis, E.; Kalyva, E., Research Methods in Special Education, Athens: Papazisi,in greek, 2006.

[27] Law 3699, "Special education and training for people with 
disabilities or special educational needs," Ministry of Education, State Printing, Gov 199/A'/2.10.2008, Athens, in greek, 2008.

[28] Christakis, K., "Children with learning difficulties," in Teaching children with difficulties: Introdution to Special Education, vol. A, Athens, Diadrasi, in greek, 2011, pp. 261-263.

[29] Christakis, K., Programms and strategies on teaching for people with special educational need and sever difficulties on learning, Athens: Diadrasi, in greek, 2013.

[30] Tanos Chr, Dyslexia and the treatment of the dyslexic student. A brief tutorial for the teacher, Athens: Gregory, in greek, 2012.

[31] Andreou, E. \& Vlachos, F , "Learning Styles of Typical Readers and Dyslexic Adolescents," Journal of Visual Literacy, vol. 32, no. 2, pp. 1-14, 2013.

[32] Ministry of Education-Pedagogigal Institute, "Methodological guidelines," in Learning Readiness Activities. Oral Speech, Psychomotor, Mental Capacity, Emotional Organization. Theacher's Book for Special Education and Training, M. Drossinou, Ed., Athens, Pedagogigal Institute, Organization Publishing of teaching books, www.pi-schools.gr, in greek, 2009, pp. 28-43. 